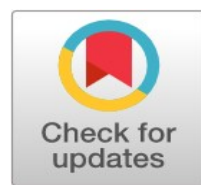

\title{
The causal effect of technology acceptance factors on the intention to use mobile application
}

\author{
Khanisara Thanyasunthornsakun ${ }^{1 *}$, Jeerapha Sornsakda ${ }^{2}$, Sawitree Boonmee ${ }^{3}$ \\ 1, 2, 3 Udonthani Rajabhat University
}

\begin{abstract}
Index Terms
Intention to use

Technology acceptance

Mobile application
\end{abstract}

Received: 26 June 2016

Accepted: 12 August 2016

Published: 27 October 2016

\begin{abstract}
The objective of this research was to study the causal effect of technology acceptance factors on the intention to use a mobile application. There were six technology acceptance factors, including perceived ease of use, subjective norm, perceived monetary value, perceived usefulness, satisfaction, and attitudes toward mobile application usage. The population and samples in this research were Thai citizens who were using the mobile application. The sampling method used was convenience sampling. The total number of samples gathered was 460 samplings using a questionnaire as a data collection tool. The collected data were analyzed with SPSS, and the structural equation model was analyzed with LISREL 8.5. The research findings indicated that the model fits empirical data with Chi-Square $=128.69, \mathrm{df}=129, \mathrm{p}$-value $=0$. 49125, RMSEA=0. 000, GFI=0. 98, AGFI=0. 95 and CFI=1. 00. The factors that had direct effects on intention to use mobile applications were satisfaction, perceived usefulness, and attitudes. The factors that had indirect effects were perceived ease of use and perceived monetary value. Moreover, the perceived ease of use also affected the perceived usefulness of mobile application usage. The perceived monetary value affected the satisfaction of the usage of the mobile application. Mobile application providers and developers should consider the applications in a variety of communication technology or productivity tools, which the developers should focus on the ease of use and usefulness.
\end{abstract}

(c) 2016 The Author(s). Published by TAF Publishing.

\section{INTRODUCTION}

Currently mobile phones play the important part in everyday communication. The value of the mobile phone market in Thailand has been continuously growing over the years, especially smartphone market. The smart phones are run on mobile operating system which allows users to install the mobile application of their choices. In cooperation with the advance development of mobile communication network technology, e.g., 4G technology, Thailand smartphone market has been rapidly expanding. According to the Kasikorn research center (2015) estimation, in 2016, the smartphone sales will rise to 17.9 - 18.7 million devices, increasing $14.7 \%-19.9 \%$ by 2015 . The smartphone market values will be approximately 93,880 - 94,480 million Baht, increasing $5.1 \%$ - $5.8 \%$ by 2015 . The increasing in the demand of smartphone will also affect the increasing in mobile application development. At 2013, Thailand mobile application and mobile development market was valued 763.80 million Baht. The majority of the market we're in lifestyle category and entertainment category, while $81.5 \%$ of mobile application were available without charge. The mobile application is the software facilitated the use of smartphones. It includes both software for general-purpose and for specific- propose software. Some of general-purpose software is bundled with the smartphone operation system. The other applications can be downloaded through mobile operation system's application market, including Apple's App Store, Google's Play Store, and Microsoft's Windows

\footnotetext{
* Corresponding author: Khanisara Thanyasunthornsakun

†Email: khanisara@gmail.com
} 
Store. Nowadays, there is the growing number of mobile users downloading mobile application for the purpose of communication, entertainment, news update, searching, financial service, and also social networking. Moreover, there are a lot of businesses launching mobile application to provide an alternative service channel and reducing service costs. The purpose of this research is to study the causal effect of technology acceptance factors on the intention to use mobile application.

\section{LITERAT URE REVIEW}

The research was applying two information technology adoptions related-theories, including Davis's Technology Acceptance Model and Ajzen's Theory of Reason Action. Davis (1989)'s Technology Acceptance Model, as well known as TAM, is the model explaining how users is making decision on accepting and adopting technology. TAM consists of two factors; perceived usefulness and perceived ease of use, affecting the attitude towards us, which is affecting the behavioral intention to use technology in the future. The perceived usefulness of mobile application refers to the level of personal beliefs on the perceived functionality or product derived from using the mobile application. The perceived ease of use of mobile application refers to the perception of mobile application users on easier, less complicated functions, and convenience in using mobile applications.Ajzen (1991) suggested the theory of reasoned action (TRA). TRA explains that beliefs and attitudes influence on behavior. The change in human behavior is the result of the change in beliefs and then human will act according to their belief as of the appropriate action. TRA explains that a person will always reflect on his reason before taking action. There are two factors related to behavior and behavioral intention, attitude toward performing the behavior and subject norm, in which a personal belief will transform into intention and intention will affect behavior. The reviews of mobile application related research showed that majority of the research were focusing on hardware and software development of mobile application in various functionalities (De Mesa, Fleras, Pagdato \& Yu, 2014; Pãvãloaia, 2013; Nourbakhsh, Mohamad Zin, Irizarry, Zolfagharian \& Gheisari, 2012; Al-Jabri \& Sohail, 2012; Lee \& Kim, 2012; Zhang, Kunjithapatham, Jeong \& Gibbs, 2011; Kenteris, Gavalas \& Economou, 2010).Some were relating to behavior and use of mobile technology and application in diverse businesses and industries (Yang \& Forney, 2013; Al-Jabri \& Sohail, 2012; Adholiya, Dave \& Singh, 2012; Kim, Ma \& Park, 2009). Another variation of mobile application research was the acceptance of mobile application technology (Almasri, 2015; Shin \& Lee, 2014; Lin \& Lu, 2015; Sun, Wang, Guo \& Peng, 2013; Jaradat, \& Al Rababaa, 2013; Adholiya, Dave \& Singh, 2012; Kim \& Garrison, 2009). The past research on factors affecting the intention to use mobile application were still scarce and not cover diverse dimension, especially social dimension and marketing dimension. Giving the review of theories and research on the mobile application, this research has applied TAM and TRA for studying on factors affecting the intention to use mobile application on Smartphone, in which the research proposed framework was shown in Figure 1. The framework was consisted of 7 variables as follows;

\section{Exogenous Variables}

- Perceived ease of use of mobile application (PEOU)

- Social norm (SN)

- Perceived monetary value of mobile application (MON)

\section{Endogenous Variables}

- Perceived usefulness of mobile application (PU)

- Satisfaction on using mobile application (SA)

- Attitude toward use of mobile application (ATU)

- Intention to use mobile application (ITN)

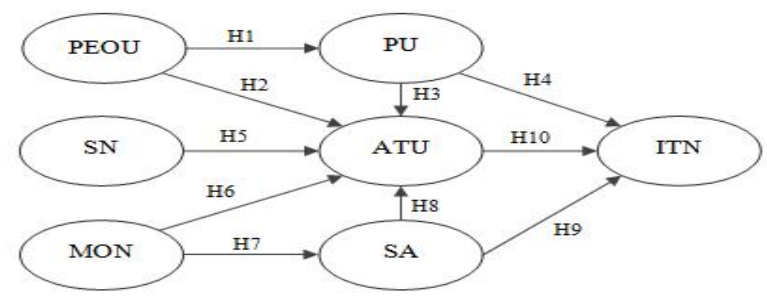

FIGURE 1. Research framework

From Figure1 the hypotheses can be summarized as follow;

H1: Perceived ease of use was affecting on perceived usefulness of mobile application.

H2: Perceived ease of use was affecting on attitude toward the use of mobileapplication.

H3: Perceived usefulness was affecting on attitude toward use of mobile application.

H4: Perceived usefulness was affecting on intention to use mobile application.

H5: Social norm was affecting on attitude toward use of mobile application.

Questionnaires were used as the data collection tool. The questionnaire items included respondent backgrounds, mobile application usage behavior intention to use mobile

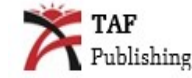


applicationand technology acceptance factors-perceived

ease of use, social norm, perceived monetary value perceived usefulness, satisfaction, and attitude towards uses of mobile application. The questionnaire was structured using 5-level Likert's rating scales.

All items in the questionnaire had index of Item Objective Congruence (IOC) between $0.8-1.00$ and the Cronbach's alpha were range $0.62-0.77$. The questionnaire was constructed Hypothesis 6 Perceived monetary value was affecting on attitude toward the use of mobile application.

H7: Perceived monetary value was affecting on satisfaction. H8: Satisfaction was affecting on attitude toward use of mobile application.

H9: Satisfaction was affecting on intention to use mobile application.

H10: Attitude was affecting on intention to use mobile application.

\section{RESEARCH METHODOLOGY}

The population of this research was approximately $9,300,000$ mobile application users based on the numbers of smartphone users under IOS, Android, and Windows mobile operating system, reported by Business Insider website in 2013. The sample size collected was 460 samples.
The sampling technique used in this research was convenience sampling in an online questionnaire format hosted by Survey can website. The link of the questionnaire or QR code was distributed on either social network website or via social network application, such as Face book, Line, and Twitter. The distribution was starting by the persons in researcher's social circle and was distributed through the social circle of respondents to reach variety of respondents.The data were analyzed by Structural Equation Modeling (SEM) to test the fitness of modelto empirical data using Linear Structure Relationship Program or LISREL.

\section{RESULTS}

From 460 respondents found that the respondents' gender proportion were not much different among female and male, $50.4 \%$ and $49.6 \%$ respectively. Majority of the respondents' age range from $20-29$ years old and $30-39$ years old, $59.6 \%$ and $20.4 \%$ respectively.The respondents' incomes mostly below 10,000 Baht, following by 10,0001 20,000 and 20,001 - 30,000 Baht, with 34.1\%, 30.9\%, and $23 \%$ respectively. Most of the respondents had been used smartphone for $1-3$ years $(68.04 \%)$ and mobile internet data expense per month range 201 - 400 Baht (47.6\%).

TABLE 1. Frequency and percentage of mobile

\begin{tabular}{|c|c|c|}
\hline Items & $\mathbf{N}$ & $\%$ \\
\hline \multicolumn{3}{|c|}{ Frequency of overall new mobile application installation } \\
\hline Less than 1 application per month & 100 & 21.7 \\
\hline 1 - 3 applications per month & 271 & 58.9 \\
\hline $4-6$ applications per month & 71 & 15.4 \\
\hline More than 6 applications per month & 18 & 4.0 \\
\hline Total & 460 & 100 \\
\hline \multicolumn{3}{|l|}{ Experience in paid for mobile application } \\
\hline Yes, paid for mobile application & 221 & 48.0 \\
\hline No, never paid for mobile application & 239 & 52.0 \\
\hline Total & 460 & 100 \\
\hline \multicolumn{3}{|c|}{ Frequency of paid mobile application installation } \\
\hline Never & 238 & 51.8 \\
\hline \multicolumn{3}{|c|}{ Less than 1 application per month 8919.3} \\
\hline $1-3$ applications per month & 118 & 25.7 \\
\hline $4-6$ applications per month & 8 & 1.7 \\
\hline More than 6 applications per month & 7 & 1.5 \\
\hline Total & 460 & 100 \\
\hline \multicolumn{3}{|c|}{ Reasons for never paid for mobile application* } \\
\hline Free application available & 183 & 37.2 \\
\hline Too expensive & 98 & 19.9 \\
\hline Trial version available & 55 & 11.2 \\
\hline Application Reviews & 49 & 10.0 \\
\hline Free substitute application available & 107 & 21.7 \\
\hline Total & 492 & 100 \\
\hline \multicolumn{3}{|l|}{ Times spent on using mobile application* } \\
\hline More than 1 hour - 1.5 hours & 116 & 25.2 \\
\hline More than 1.5 hours -2 hours & 157 & 34.1 \\
\hline More than 12 hours & 109 & 23.7 \\
\hline Total & 460 & 100 \\
\hline
\end{tabular}


Table 1 shows mobile application usage behavior. The results indicated that the respondents were mostly installing new mobile application around 1 - 3 applications per month. Almost half of the respondents paid for mobile application. The majority of respondents paid for new mobile application less that once a month. The major reason of not paid for the mobile application were that there were free application available for download and if there was no free application, there were substitute application available with no charge. Table 2 shows the findings of intention to use mobile application and technology acceptance factors which were perceived ease of use of mobile application, social norm, perceived monetary value of mobile application, perceived usefulness of mobile application, satisfaction on using mobile applications, attitude toward the use of mobile application. The findings indicated that the average of intention to use mobile application was 4.19 and the perceived usefulness of mobile application rated highest amongst technology acceptance factors following by the perceived monetary value, with the average of 4.36 and 4.30 , respectively. On the other hand, the social norm factor got the lowest average of 3.93 .

TABLE 2 . Mean, standard deviation of in intention to use mobile application and technology acceptance factors

\begin{tabular}{lcc}
\hline \hline Factors & Mean & Standard deviation \\
\hline Intention to use mobile application (ITN) & 4.19 & .757 \\
Technology acceptance factors & & \\
1) Perceived ease of use of mobile application (PEOU) & 4.02 & .809 \\
2) Social norm (SN) & 3.93 & .768 \\
3) Perceived monetary value of mobile application (MON) & 4.30 & .805 \\
4) Perceived usefulness of mobile application (PU) & 4.35 & .688 \\
5) Satisfaction on using mobile application (SA) & 4.06 & .771 \\
6) Attitude toward use of mobile application (ATU) & 4.22 & .711 \\
\hline \hline
\end{tabular}

The result of structural equation modelling analysis in Figure 1 indicated that the proposed model is valid and well fitted to empirical data $\left(X^{2}=128.69, d f=129, p\right.$-value $=0.49$
$\mathrm{X}^{2} / \mathrm{df}=0.99, \mathrm{GFI}=0.98, \mathrm{AGFI}=0.95, \mathrm{CFI}=1.00$, RMSEA $=0.000, \mathrm{RMR}=0.016, \mathrm{CN}=591.37)$. This model exhibits acceptable levels of fits suggest by Byrne (1998).

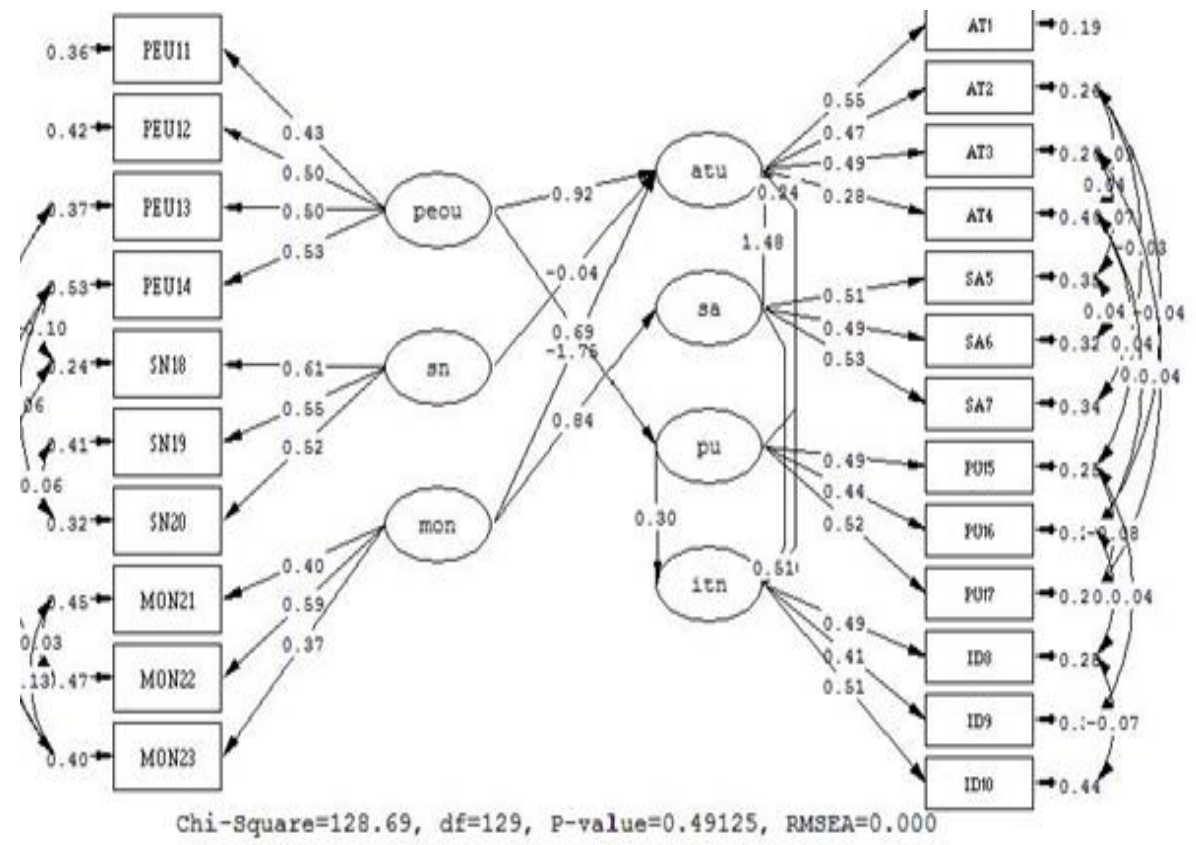

FIGURE 2 . Analysis output of structural equation model 
TABLE 3. Mean, standard deviation of in intention to use mobile application and technology acceptance factors

\begin{tabular}{|c|c|c|c|c|c|c|c|c|}
\hline \multirow[t]{2}{*}{ Endogenous Variables } & \multirow[t]{2}{*}{ Effects } & \multicolumn{7}{|l|}{ Exogenous Variables } \\
\hline & & ATU & SA PU & ITN & PEOU & SN & MON & \\
\hline & $\mathrm{DE}$ & $0.20^{* *}$ & $0.51^{* *}$ & $0.30^{* *}$ & - & - & - & - \\
\hline \multirow[t]{4}{*}{ ITN } & IE & - & 0.29 & 0.05 & - & $0.42^{* *}$ & -0.01 & $0.33^{* *}$ \\
\hline & $\mathrm{TE}$ & $0.20 * *$ & $0.81^{* *}$ & $0.35^{* *}$ & - & $0.42^{* *}$ & -0.01 & $0.33^{* *}$ \\
\hline & $\mathrm{R} 2=0.78$ & & & & & & & \\
\hline & DE & - & $1.48^{* *}$ & $0.24^{* *}$ & $-0.92 *$ & - & 0.04 & $-1.75^{* *}$ \\
\hline \multirow[t]{4}{*}{ ATU } & IE & - & - & - & - & $0.16^{* *}$ & - & $1.25^{* *}$ \\
\hline & TE & - & $1.48^{* *}$ & $0.24^{* *}$ & - & $1.08^{* *}$ & -0.04 & -0.50 \\
\hline & $\mathrm{R} 2=0.71$ & & & & & & & \\
\hline & $\mathrm{DE}$ & - & - & - & - & - & - & $0.80^{* *}$ \\
\hline \multirow[t]{4}{*}{ SA } & IE & - & - & - & - & - & - & - \\
\hline & $\mathrm{TE}$ & - & - & - & - & - & - & $0.80^{* *}$ \\
\hline & $\mathrm{R} 2=0.64$ & & & & & & & \\
\hline & $\mathrm{DE}$ & - & - & - & - & $0.69^{* *}$ & - & - \\
\hline \multirow[t]{3}{*}{ PU } & IE & - & - & - & - & - & - & - \\
\hline & $\mathrm{TE}$ & - & - & - & - & $0.69 * *$ & - & - \\
\hline & $\mathrm{R} 2=0.48$ & & & & & & & \\
\hline
\end{tabular}

$\overline{\mathrm{DE}}=$ Direct Effect, IE = Indirect Effect, TE = Total Effect, ${ }^{*} \mathrm{p}<0.05,{ }^{* *} \mathrm{p}<0.01$

Table 3 shows the causal effects of structural equation model analysis of the technology acceptance factors to the intention to use mobile application factors. The findings indicated that the factors that had positive direct effects on intention use mobile application were satisfactory, perceived usefulness, and attitude toward the use of mobile application, with the effect of $0.51,0.30$, and 0.20 , respectively. The factors that had a positive indirect effect to the intention to use mobile application were perceived ease of use and perceived monetary value, with the effect of 0.42 and 0.33 , respectively. All five factors had total effect to the intention to use mobile application, in which can be explained the variance of intention to use at $78.0 \%$.

The factors that had the direct and positive effect on the attitude toward use of mobile application on Smartphone were satisfaction, the perceived ease of use, and perceived usefulness, with the effect of $1.48,0.92$, and 0.24 respectively. The factor that had the negative direct effect was the perceived monetary value, with the effect of -1.75 . The factors that had an indirect effect on attitude toward the use of mobile application were perceived monetary value and perceived ease of use, with the effect of 1.25 and 0.16 , respectively. Factors that had the total effect on attitude toward use of mobile application were satisfaction, perceived usefulness, and perceived ease of use, in which can be explained the variance of attitude to use at $71.0 \%$. A factor had a direct effect on satisfaction on using mobile application was perceived monetary value with the positive effect of 0.80 and can explain the varianceof satisfaction at $64.0 \%$.Lastly, a factor that had a direct effect on perceived usefulness was a perceived ease of use factor with the positive effect of 0.69 and can explain the variance of perceived usefulness at $48.0 \%$.

\section{The Finding of Hypotheses Testing}

Hypothesis 1 proposed that perceived ease of use was affecting on perceived usefulness of mobile application. The finding indicated that the perceived ease of use had a positive effect on the perceived usefulness (the effect size $=$ 0.69 , standard error $=0.07$, $t$-value $=10.58$ ) .

Hypothesis 2 proposed that perceived ease of use was affecting on attitude toward use of mobile application. The finding indicated that the perceived ease of use had a positive effect on the attitude toward use of mobile application (the effect size $=0.92$, standard error $=0.37$, $\mathrm{t}$-value $=2.49$ ).

Hypothesis 3 proposed that perceived usefulness was affecting on attitude toward use of mobile application. The finding indicated that the perceived usefulness had a positive effect on attitude toward use of mobile application (the effect size $=0.24$, standard error $=0.08$, $t$-value $=2.82$ ) .

Hypothesis 4 proposed that perceived usefulness was affecting on intention to use mobile application. The finding indicated that the perceived usefulness had a positive effect on the intention to use mobile application (the effect

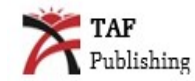


size $=0.30$, standard error $=0.07$, t-value $=4.49$ ) .

Hypothesis 5 proposed that social norm was affecting on attitude toward use of mobile application. The finding indicated that the social norm had not effected on the attitude toward use of mobile application (the effect size $=$ -0.14 , standard error $=0.22$, $\mathrm{t}$-value $=-0.19$ ) .

Hypothesis 6 proposed that perceived monetary value was affecting on attitude toward use of mobile application. The finding indicated that the perceived monetary value had a negative effect on the attitude toward use of mobile application (the effect size $=-1.75$, standard error $=0.58$, $\mathrm{t}$-value $=-3.03$ ).

Hypothesis 7 proposed that perceived monetary value was affecting on satisfaction. The finding indicated that the perceived monetary value had a positive effect on the satisfaction (the effect size $=0.80$, standard error $=0.07$, $t$-value $=11.69$ ).

Hypothesis 8 proposed that satisfaction was affecting on attitude toward use of mobile application. The finding indicated that the satisfaction on using mobile application had a positive effect on the attitude toward use of mobile application (the effect size $=1.48$, standard error $=0.38$, $\mathrm{t}$-value $=3.89$ ).

Hypothesis 9 proposed that satisfaction was affecting on intention to use mobile application. The finding indicated that the satisfaction had a positive effect on the intention to use mobile application (the effect size $=0.51$, standard error $=0.10$, $\mathrm{t}$-value $=5.22$ ) .

Hypothesis 10 proposed that attitude was affecting on intention to use mobile application. The finding indicated that the attitude toward use of mobile application had a positive effect on the intention to use mobile application (the effect size $=0.20$, standard error $=0.09$, $\mathrm{t}$-value $=2.17$ ) .

\section{DISCUSSION AND CONCLUSION}

The attitude toward use of mobile application was affecting the intention to use mobile application on Smartphone because the samples recognize the usefulness of mobile application in various functions such as entertainment, communication, information and news attainment, education, including using them as a part of business transaction tool. The attitude toward the use of mobile application derived from 1) a positive impression on the ability of application met the usage needs 2) the application functionality 3 ) the varieties of applications 4) social factors 5) application fast responding 6) unsophisticated functions 7) ease of installation 8) ease of acquisition and download and 9) smartphone users' knowledgeable of application functions. When the samples perceived that usefulness of mobile application, it will lead to the positive intention to use mobile application, which comparable to David (1989)'s technology acceptance model (TAM). David's TAM suggested that the intention to use technology was influenced by the attitude toward technology and perceived usefulness of technology, which will finally cause the usage behavior. The finding also conforms to Ajzen (1991) explanation of a person acts upon his reason. A person will act according to his or her belief that he or she should act because a person will always reason before take action. The change in human behavior is the result of change in attitudes and beliefs. Islam, Kim Cheng Low \& Hasan (2013) as well stated that the relationship between perceived usefulness and intention to use were moderated by the attitudes towards use of mobile phone services. Likewise, the findings of Lin \& Lu (2015) on the study of impacts on the user acceptance of mobile social networking sites. Their findings described that mobile convenience, service compatibility, security risk and cognitive effort were indirectly affecting user acceptance of social network, which also moderated by the on pleasure value and utility value, or in other word, the perceived enjoyment and the perceived usefulness. Hong, Thong, Moon \& Tam (2008) also found similar findings that perceived ease of use, perceived usefulness and perceived enjoyment affected attitude toward the continuous usage of mobile data service and different categories of mobile service affected the usage context differently.

The satisfaction was influencing the attitude toward the use of mobile application. The procedures of services, mobile application download activities, and the ability of application in responding to usage requirement were the causes of satisfaction. In which, the satisfaction impacted on intention to behave continuously. The findings conformed to Parasuraman, Zeithaml \& Berry (2002)'s SERVQUAL, which satisfaction was principally leading the perception of service quality. Anderson \& Mittal (2000) stated that customer satisfaction was an emotional response to experience which will influence loyalty, positive responses, financial performance and margins of the organization. Lin \& Wu (2011) studied the factors affecting online customer satisfaction. Their study found that the satisfaction in using smart phone applications affected the intention to use mobile application. Their samples showed satisfaction with the services of the App store, Play store and Windows phone store, and satisfaction on download procedures and times spent on searching for mobile application. Moreover, Lee \& Huang (2014) found that the perceived function value was signifi- 
cantly affecting on satisfaction, which lead to the continued intention to use social networks.

The perceived usefulness factor showed the significant effects on both attitudes toward the use of mobile application and intention to use mobile application. When users perceived the usefulness, value of the mobile application functions, for example, education application or communication application, the users would have a positive attitude towards the mobile application usage, in which lead to intention to use. The findings conform to Davis (1989)'s Technology Acceptance Model (TAM). Davis suggested that attitude towards technology affected the intention to use technology, while the perceived usefulness and perceived ease of use were affecting the attitude. The Ajzen (1991)'s theory of Reasoned Action also indicated that consumer perceived usefulness and perceived ease of use related to the attitude toward technology acceptance and such attitude led to the behavioral intention to use the technology. Venkatesh \& Davis (2000) mentioned that the perceived usefulness had a direct effect on attitudes toward technology. Moreover, Islam, Kim Cheng Low \& Hasan (2013) similarly found that perceived usefulness significantly affected the intention to use mobile phone service, which the effect was moderated by the attitude toward mobile phone service usage.

The perceived ease of use had an indirect effect on intention to use mobile application through the perceived usefulness and attitude toward mobile applications. Users perceived the ease in using the mobile application included perception of clear and explicit details, easy to understand, uncomplicated using process or its availability regardless time and places. When users perceived these values, it will lead to the change in beliefs and attitude which affecting the intention to use mobile application. The findings conform to Davis (1989)'s TAM. TAM mentioned that perceived ease of use was the factor affecting perceived usefulness. In other words, the easiness and complication of application would lead to the personal belief on how to utilize the application, which from the previous discussion; the perceived usefulness was affecting the behavioral intention to use mobile application.

Venkatesh \& Davis (2000) also found that perceived ease of use had a direct effect on perceived usefulness. Currently mobile applications are rapidly advancing and providing various functions corresponding to diversity of user requirement. When there are many applications available to pick, users tend to pick the application that aligns with their requirement most. If the users perceived that the application is not useful, the user would unlikely to use the application, regardless of the recommendation of acquaintances. Therefore, the social norm was found no effect on neither attitude toward the use of mobile application nor intention to use, which follow Fishbein \& Ajzen (1975)'s findings. They stated that social factor was the estimation of the degree of a person would follow a reference group. It depends on the beliefs of a reference group's attitude toward their normative belief and motivation to comply. Some behavior was defined by the personal attitude toward such behavior more than complying the reference group. And some behavior might be influenced by personal attitudes toward such behavior as much as complying the reference group. This means that the importance of both personal attitudes versus compliance with reference group might vary from one person to another.

Lastly, the perceived monetary value factor had an indirect effect on intention to use mobile application through an attitude toward the use of mobile application and satisfaction. Users tend to pay for mobile applications which believed its functions worth the price. Sometime users pay for mobile application when it was on discount. The findings conform to Richard L. Oliver (1977; 1980)'s Expectation confirmation theory. It explained that function of satisfaction was consisted of the post-purchase adoption expectation, perceived performance, and disconfirmation of beliefs. The satisfaction on experience with products or service influenced the intention to reuse such product or services. Faziharudean \& Li-Ly (2011) also found that the perceived monetary value of mobile data service was an important for customers considering the pricing was appropriate and worth the service expectation. Furthermore, Hong, Thong, Moon \& Tam (2008) similarly found that customers' intention to continue usage of mobile data services was affected by attitude, social influence, media influence, perceived mobility and perceived monetary value.

\section{Recommendations for Further Application}

Mobile application providers and developers should consider the applications in variation of communication technology or the productivity tools, which the developers should focus on the ease of use and usefulness. Moreover, mobile application providers should build the advertisement channel via the groups, communities, or organizations that close to mobile application usage to motivate the real use of mobile applications and marketing communication. 
Recommendations for Further Research

This study only focused on the study of causal factors affecting intention to use mobile application on the smartphone. The sample in this study was different in age range, which might affect the use of mobile application.
The further study on the comparison among age group might benefit the further understanding on the mobile application usage. Moreover, the longitudinal study would provide the understanding of change in mobile usage, though times and technology advancement.

\section{REFERENCES}

Adholiya, A., Dave, P., \& Singh, N. 2012. Mobile money as M-Commerce machinery: Technology acceptance model analysis with reference to Udaipur users at Rajasthan. International Journal of Applied Services Marketing Perspectives, 1(2): 195-203.

Ajzen, I. 1991. The theory of planned behavior. Organizational Behavior \& Human Decision Processes, 50(2): 179-211. DOI: $10.1016 / 0749-5978(91) 90020-T$

Al-Jabri, I.M., \& Sohail, M.S. 2012. Mobile banking adoption: Application of diffusion of innovation theory. Journal of Elec- tronic Commerce Research, 13(4): 379-391.

Almasri, A.K.M. 2015. A hybrid proposed framework based on Quality Factors (QF) and Technology Acceptance Model (TAM) for mobile learning process: Higher education students in Jordanian universities. International Journal of Information Business \& Management, 7(3): 200-212.

Davis, F.D. 1989. Perceived usefulness, perceived ease of use and user acceptance of information technology. MIS Quarterly, 3(3): 319-340. DOI: 10.2307/249008

Faziharudean, T.M., \& Li-Ly, T. 2011. Consumers' behavioral intentions to use mobile data services in Malaysia. African Journal of Business Management, 5(5): 1811-1821.

Fishbein, M., \& Ajzen, I. 1975. Belief, attitude, intention, and behavior: An introduction to theory and research. Reading, MA: Addison-Wesley.

Hong, S.J., Thong, J.Y., Moon, J.Y., \& Tam, K.Y. 2008. Understanding the behavior of mobile data services consumers. Infor- $\quad$ mation Systems Frontiers, 10(4): 431-445. D0I: 10.1007/s10796-008-9096-1

Islam, Z., Kim Cheng Low, P., \& Hasan, I. 2013. Intention to use advanced mobile phone services (AMPS). Management De- cision, 51(4): 824-838. DOI: 10.1108/00251741311326590

Jaradat, M.I.R.M., \& Al Rababaa, M.S. 2013. Assessing key factor that influence on the acceptance of mobile commerce based on modified UTAUT. International Journal of Business \& Management, 8(23): 102-112. D0I:10.5539/ijbm.v8n23p102

Kenteris, M., Gavalas, D., \& Economou, D. 2011. Mytilene E-guide: A multiplatform mobile application tourist guide exem plar. Multimedia Tools \& Applications, 54(2): 241-262. D0I:10.1007/s11042-010-0519-x

Kim, S., \& Garrison, G. 2009. Investigating mobile wireless technology adoption: An extension of the technology acceptance model. Information Systems Frontiers, 11(3): 323-333. D0I:10.1007/s10796-008-9073-8

Kim, J., Jin Ma, Y., \& Park, J. 2009. Are US consumers ready to adopt mobile technology for fashion goods? An integrated theoretical approach. Journal of Fashion Marketing \& Management: An International Journal, 13(2): 215-230. DOI: $10.1108 / 13612020910957725$

Lee, C.L., \& Huang, M.K. 2014. A nonlinear relationship between the consumer satisfaction and the continued intention to use SNS services: The moderating role of switching cost. International Journal of Electronic Business Management, 12(2): 90-101.

Lee, S., \& Kim, K. 2012. Mobile agent based framework for mobile ubiquitous application development. Telecommunication Systems, 51(2-3): 137-146. DOI: 10.1007/s11235-011-9423-6

Lin, K.Y., \& Lu, H.P. 2015. Predicting mobile social network acceptance based on mobile value and social influence. Internet Research, 25(1): 107-130. DOI: 10.1108/IntR-01-2014-0018

Lin, J.S.C., \& Wu, C.Y. 2011. The role of expected future use in relationship-based service retention. Managing Service Quality: An International Journal, 21(5): 535-551. D0I:10.1108/09604521111159816 
De Mesa, L.D., Fleras, A.M., Pagdato, K.P. , \&Yu, M.R.B. 2014. Design and development of an intranet-based IT asset manage- $\quad$ ment system with mobile application. International Journal of Innovation, Management \& Technology, 5(6): 460- 464. DOI:10.7763/IJIMT.2014.V5.559

Nourbakhsh, M., Mohamad Zin, R., Irizarry, J., Zolfagharian, S., \& Gheisari, M. 2012. Mobile application prototype for on-site information management in construction industry. Engineering, Construction \& Architectural Management, 19(5): 474-494. DOI: 10.1108/09699981211259577

Oliver, R.L. 1977. Effect of expectation and dis confirmation on post exposure product evaluations: An alternative interpretation. Journal of Applied Psychology, 62(4): 480-489.

Oliver, R.L. 1980. Conceptualization and measurement of disconfirmation perceptions in the prediction of consumer satisfaction. Paper presented at the Fourth Annual Conference on Consumer Satisfaction, Dissatisfaction, and Complaining Behavior, School of Business, Indiana University, Bloomington, US. DOI:10.1037/0021-9010.62.4.480

Parasuraman, A., Zeithaml, V., \& Berry, L. 2002. SERVQUAL: A multiple-item scale for measuring consumer perceptions of service quality. Retailing: Critical Concepts, 64(1): 12-37.

Pãvãloaia, V. D. 2013. Methodology approaches regarding classic versus mobile enterprise application development. Inforica Economica, 17(2): 59-72. DOI: 10.12948/issn14531305/17.2.2013.05

Shin, S., \& Lee, W. J. 2014. The effects of technology readiness and technology acceptance on NFC mobile payment services in Korea. Journal of Applied Business Research, 30(6): 1615-1635. D0I:10.19030/jabr.v30i6.8873

Sun, Y., Wang, N., Guo, X., \& Peng, Z. 2013. Understanding the acceptance of mobile health services: A comparison and integration of alternative models. Journal of Electronic Commerce Research, 14(2): 183-187.

Venkatesh, V., \& Davis, F. D. 2000. A theoretical extension of the technology acceptance model: Four longitudinal field studies. Management Science, 46(2): 186-204. DOI: 10.1287/mnsc.46.2.186.11926

Yang, K., \& Forney, J.C. 2013. The moderating role of consumer technology anxiety in mobile shopping adoption: Differential effects of facilitating conditions and social influences. Journal of Electronic Commerce Research, 14(4): 334-347.

Zhang, X., Kunjithapatham, A., Jeong, S., \& Gibbs, S. 2011. Towards an elastic application model for augmenting the computing capabilities of mobile devices with cloud computing. Mobile Networks \& Applications, 16(3): $270-284$. DOI: $10.1007 /$ s11036-011-0305-7

— This article does not have any appendix. - 